Int. J. Electrochem. Sci., 14 (2019) 9355 - 9368

\title{
Electrochemical Preparation of Iron-Supported Carbon-Cloth Electrode and Its Application in the In-Situ Production of Hydrogen Peroxide
}

\author{
Ikenna Chibuzor Emeji ${ }^{1}$, Onoyivwe Monday Ama ${ }^{2,3}$, Peter Ogbemudia Osifo ${ }^{1}$, \\ Suprakas Sinha Ray ${ }^{2,3}$, Orlando García-Rodríguez, Olivier Lefebvre ${ }^{4}$ \\ ${ }^{1}$ Department of Chemical Engineering, Vaal University of Technology, Private Mail Bag X021, \\ Vanderbijlpark 1900, South Africa. \\ ${ }^{2}$ Department of Applied Chemistry, University of Johannesburg, Doornfontein 2028, South Africa. \\ ${ }^{3}$ DST/CSIR National Centre for Nano-structured Materials, Council for Scientific and Industrial \\ Research, Pretoria 0001, South Africa. \\ ${ }^{4}$ Centre for Water Research, Department of Civil and Environmental Engineering, National University \\ of Singapore, No. 1 Engineering Dr. 2, Singapore, 117576. \\ *E-mail: emejiiyk@gmail.com, onoyivwe4real@gmail.com
}

doi: $10.20964 / 2019.09 .52$

Received: 6 March 2019 / Accepted: 12 July 2019 / Published: 5 August 2019

This study describes how carbon-cloth (CC) electrode was demonstrated to have good electrical conductivity using linear sweep voltammetry (LSV). Its electrocatalytic activity was evaluated toward the generation of hydrogen peroxide $\left(\mathrm{H}_{2} \mathrm{O}_{2}\right)$ via oxygen reduction reaction by two electrons. Electrochemical deposition of iron on an electrode surface was vital in the synthesis of iron modified carbon-cloth electrode, in that the process was used to eliminate iron salts in solution as precursors for the homogeneous Fenton process because of its large solid sludge formation. Iron electrodeposition potential was found to be; $-1.3 \mathrm{~V} \leqq \mathrm{E} \leqq 1.00 \mathrm{~V}$ and $-1.8 \mathrm{~V}$ to $1 \mathrm{~V}$. Chronoamperometry technique was successfully used to deposit $0.1 \mathrm{M}$ of iron on the CC electrode. The following materials synthesised, iron supported carbon-cloth electrodes were characterised. Using a scanning electron microscope (SEM) and energy dispersive X-Ray spectroscopy (EDX) analysis, the morphology, elemental distribution, and composition of the modified CC electrode were observed. The availability of oxygen-containing functional groups on the modified electrode was confirmed by X-ray photoelectron spectroscopy (XPS) analysis. These functional groups on CC electrode act as oxygen reduction reaction (ORR) active sites for in-situ $\mathrm{H}_{2} \mathrm{O}_{2}$ promotion, electro-generation, and activation. Hence, the magnitudes of nitrogen-tocarbon $(\mathrm{N} / \mathrm{C})$ and oxygen-to-carbon $(\mathrm{O} / \mathrm{C})$ ratios were calculated to be $0.02 \%$ and $0.29 \%$ respectively, indicating high oxygen content as compared to nitrogen. Therefore, the techniques and application of using low-cost carbon-cloth materials, to support iron particles, for in-situ hydrogen peroxide generation suggest innovation. 
Keywords: Hydrogen peroxide $\left(\mathrm{H}_{2} \mathrm{O}_{2}\right)$, Carbon-cloth electrode, Oxygen reduction reaction (ORR), Electrodeposition,

\section{FULL TEXT}

(C) 2019 The Authors. Published by ESG (www.electrochemsci.org). This article is an open access article distributed under the terms and conditions of the Creative Commons Attribution license (http://creativecommons.org/licenses/by/4.0/). 